\title{
Comparative Analysis of Abrasive Wear Using Response Surface Method and Artificial Neural Network
}

\author{
Dinesh Y. Dhande ${ }^{1}$ (1) Mangesh R. Phate ${ }^{1} \cdot$ Nazaruddin Sinaga $^{2}$
}

Received: 23 August 2020/ Accepted: 20 January 2021

(C) The Institution of Engineers (India) 2021

\begin{abstract}
This research work deals with the application of response surface methodology and artificial neural network-based mathematical modelling of abrasive wear volume for a dry sliding wear of PTFE pin. The experiments were designed based on central composite design. The disc speed, load and sliding distance have been selected as parameters of the process, while the abrasive wear volume has been selected as an output. The ANNOVA test revealed that the disc speed has maximum influence and contributes $28.21 \%$ of abrasive wear volume followed by load, which contributes $12.83 \%$ of abrasive wear volume. The two models were compared using root mean square error and absolute standard deviation. The artificial neural network-predicted values of abrasive wear volume were found in close agreement with the actual experimental results as compared to response surface methodology predicted results and hence recommended for the similar studies.
\end{abstract}

Keywords Abrasive wear - Artificial neural network · Pin on disc $\cdot$ Response surface method - Wear volume

Dinesh Y. Dhande

dydhande@aissmscoe.com

1 Department of Mechanical Engineering, AISSMS College of Engineering, Pune, India

2 Department of Mechanical Engineering, Diponegoro University, Semarang 50275, Indonesia

\section{Introduction}

In the engineering field, for critical parameters analysis, software methods, including artificial neural networks and fuzzy logic circuits, are becoming increasingly popular. The reason for this is that these models can address a variety of dynamic problems in contrast to traditional mathematical models at much lower running costs. Different forms of wear are given, including adhesive, abrasive, fatigue wear and fretting. Abrasive wear for composites, coatings, instruments, aircraft manufacturing, bone and hip implants, and automotive parts are of vital significance because it determines components' longevity or performance. This is generally checked experimentally, as process parameters like sliding lengths, speed, material qualities and surface texture influence the wear [1]. In the study of wear analysis, several mathematical modelling techniques have been developed. Some of them include continuum mechanics [2, 3], analysis [4, 5], and stochastic [6], multidimensional [7], atomic and molecular kinetics [8], finite element modelling [9], boundary element system [10], dimension reduction method [11], symptom modelling [12] and other methods listed by Popov [13] and Vakis et al. [14]. However, since surface phenomena are complex, their mathematical modelling is still limited.

In recent years, the use of artificial intelligence (AI) technology has become popular in tribological studies $[15,16]$. Jones et al. [17] implemented an artificial neural network (ANN) system to model wear behaviour and predict life data. Accurate prediction of wear behaviour by ANN provides an alternative to the current time-consuming testing methods. Since then, the technique has been successfully used in the tribology field, which includes wear of polymer composites [18-22], tool wear [23], online wear rating [24], brake performance [25, 26], corrosion of 
polymers [27], wheel and rail wear [28], copper-aluminium nano-composite wear rate [29], wear of heattreated aluminium-clay composites [30] and wire electrical discharge process [31-33]. Bhaumik et al. [34] implemented the technique for predicting the coefficient of friction for various friction modifiers. Recently, sliding wear is predicted by Argatov et al. [35] using this method.

Another mathematical technique to investigate the influence of process parameters on the process performance is the response surface methodology, where the smaller number of tests is performed [36-38]. The Box-Behnken technique used to analyse two body abrasive wear actions of glass fibre epoxy composites using the reaction surface methodology. The findings revealed that the load is greater than the sliding distance when weight loss is involved [39]. TiB2 particulate reinforced aluminium composite alloy matrix manufactured by centrifuge cast was introduced to assess three-body abrasive wear [40].

The purpose of the present study is to demonstrate the modelling capability of artificial neural network (ANN) technique and response surface methodology (RSM) by implementing it for analysis of abrasive wear volume. The experimental wear volume was calculated based on the sample weight loss during the test interval. The test results obtained were used to train the ANN model and develop RSM model. The ANN predicted results were found to closely resemble the test results. The study confirmed that the ANN technique effectively predicts critical process parameters as compared to RSM and should be widely used in tribology studies to avoid damage to test methods and materials and to reduce testing time.

\section{Materials and Method}

\section{Experimental Set Up}

In this work, a developed pin-on-disc test set-up (Fig. 1) was utilised for experimentation. The test set-up has a stationary vertical pin positioned perpendicular to a horizontally kept rotating circular disc to form a two-body wear

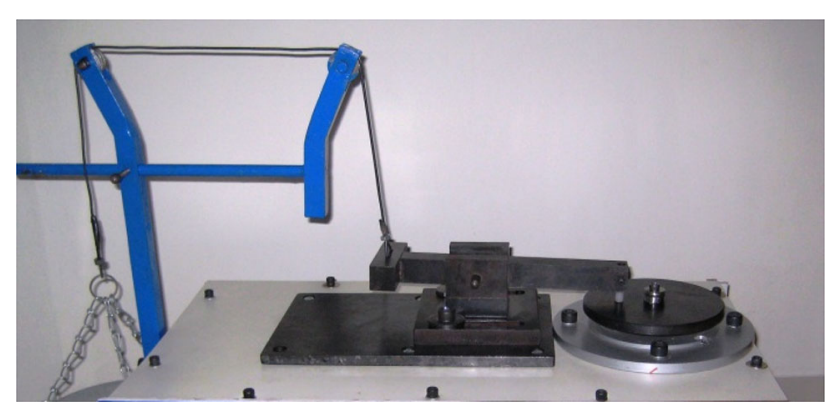

Fig. 1 Experimental test set-up system. The cylindrical pin specimen was used for the study with an $8 \mathrm{~mm}$ diameter and length of $30 \mathrm{~mm}$. The pin was prepared by cutting long rods of the material to the required length. The disc was cut from a circular rod, of diameter $140 \mathrm{~mm}$, to a thickness of $11 \mathrm{~mm}$. The disc was surface ground on the conventional grinding machine. The specific load in the pan was transferred via an arm to keep the pin pressed against the disc. All foreign particles were removed from the pin as well as disc before every run. The disc was mounted on a permanent magnet direct current (PMDC) motor. A speed control unit is consisting of AC to DC power transformer and a thermistor drive with a potentiometer. The material used for the pin in this study was poly-tetra-fluoro-ethylene (PTFE) due to its easy availability. The pin wear volume was measured using a digital scale (TAPSON 200T, with a resolution of $0.1 \mathrm{mg}$ ), and reduction in length was measured using a micrometre (with a resolution of $0.02 \mathrm{~mm}$ ). Appropriate linear dimensions of the pin were measured before and after the tests. The experimental test conditions are listed in Table 1.

The measurements were taken as per ASTM G99 standard using in-house tribometer. The cylindrical pins with dimensions of roughly $8 \mathrm{~mm}$ or $30 \mathrm{~mm}$ were prepared from a PTFE bar. A small steel disc having ample roughness (treated with 600-grit sandpaper) was used as a sliding counterpart. Dry sliding wear experiments, with different input parameters, such as load, sliding velocity and sliding distance, were performed. The conditions for the testing are shown in Table 1. Prior to and after the procedure, the weight of the sample was measured with an analytical balance (TAPSON 200T) of $\pm 0.1 \mathrm{mg}$ precision. The loss in pin volume was estimated using following empirical relation (Eq. 1):

Wear Volume $(V)=\frac{W_{1}-W_{2}}{\rho}$

where $W_{1}$ is the sample weight before the test, $W_{2}$ is the weight after the test and $\rho$ denotes the density of the sample.

\section{Response Surface Method}

The response surface methodology (RSM) is a useful tool for modelling which integrates both computational and mathematical approaches. It is a very beneficial tool to evaluate industrial problems where many parameters will affect the so-called response output. Process output goals may also be directly achieved through RSM. In the RSM, correlation between the desired response and independent input variables is:

$Y=f(S, L, D)$ 
Table 1 Experimental conditions

\begin{tabular}{ll}
\hline Parameters & Operating conditions \\
\hline Normal load (N) & $4.905,9.81,14.715,19.620,24.525$ \\
Disc speed (RPM) & $250,500,750,1000,1250$ \\
Sliding velocity (m/s) & 0.125 to 2.70 \\
Wear track radius (mm) & 25 to 60 \\
Pin material & PTFE \\
Surface conditions & Dry \\
Sliding distance (m) & $432 \mathrm{~m}, 864 \mathrm{~m}, 1732 \mathrm{~m}$ \\
Load & $0.5 \mathrm{~kg}, 1 \mathrm{~kg}, 1.5 \mathrm{~kg}, 2 \mathrm{~kg}, 2.5 \mathrm{~kg}$ \\
Disc speed (RPM) & $250,500,750,1000,1250$ \\
Disc material & Mild steel \\
\hline
\end{tabular}

where $Y$ is the desired abrasive wear (response), $f$ is the response function and $S, L$ and $D$ represent speed, load and sliding distance. A second-order response surface model is used to model the process and is given by the following equation.

$Y=\beta_{0}+\sum_{i=1}^{k} \beta_{i} X_{i}+\sum_{i=1}^{k} \beta_{i} X_{i}^{2}+\sum_{i<j} \sum_{<2}^{k} \beta_{i j} X_{i} Y_{i}+\varepsilon$

where $Y$ is the value of the expected output and $X_{1}, X_{2} \ldots$ are the values of process variables. $\beta$ represents the regression coefficient and $\varepsilon$ is the residue, which results from the experimental error. The central composite designs (CCD) are especially suitable to estimate secondary reaction surfaces since they are very effective in presenting detailed insight about influence of each process variable and an overall test error in the minimal tests trials. The independent process variables and design levels are shown in Table 2. Three independent process variables, namely speed $(N)$, load $(W)$ and sliding distance $(L)$ were used. Each process variable had three levels, viz. $-1,0$ and + 1. The significance of the input parameters was assessed by means of variance analysis (ANOVA). Minitab 2018 programme was used to evaluate, create the design matrix and fit the experimental data into a second-order polynomial.

Table 2 Process variables and design levels

\begin{tabular}{llllll}
\hline Process variables & Notation used & Unit & \multicolumn{3}{l}{ Limits } \\
\cline { 3 - 5 } & & & -1 & 0 & +1 \\
\hline Speed & $S$ & RPM & 250 & 750 & 1250 \\
Load & $L$ & N & 4.905 & 14.715 & 24.525 \\
Sliding distance & $D$ & $\mathrm{~m}$ & 432 & 1081 & 1730 \\
\hline
\end{tabular}

\section{Artificial Neural Network Model}

Artificial neural networking is a sophisticated computer technique similar to the human neural structure to improve performance. The main component of ANN is artificial neurons. Neurons are linked to each other by weightbearing functions. In $\mathrm{ANN}$, a real number is the input signal. Some nonlinear equation of the sum of its inputs calculates the output of each neuron. Neurons and links normally weigh in compliance with the training process and change the learning parameter. Each neuron receives inputs from multiple neurons, multiplies them by assigned weights and sends them to one or more neurons, depending on the structure of the network. Some neurons may use an activation function in the output before being sent to the next variable. The activation function can be selected from known functions such as Linear, tan-sigmoid, Log-Sigmoid and ReLU. The involved weights are modified in such a way that the neuron and subsequently the ANN can properly represent the output variable in the training samples. The developed ANN structure and individual neural architecture is shown in Fig. 2.

The sum of the product of input value and the corresponding weight is given by net input (Net) $j$, which is translated into the implementing value. $W_{i j}$ indicates weight in the forward layer of the connection between the $i^{\text {th }}$ neuron and the $j^{\text {th }}$ neuron. The output of the $j^{\text {th }}$ neuron is calculated using Eq. 4:

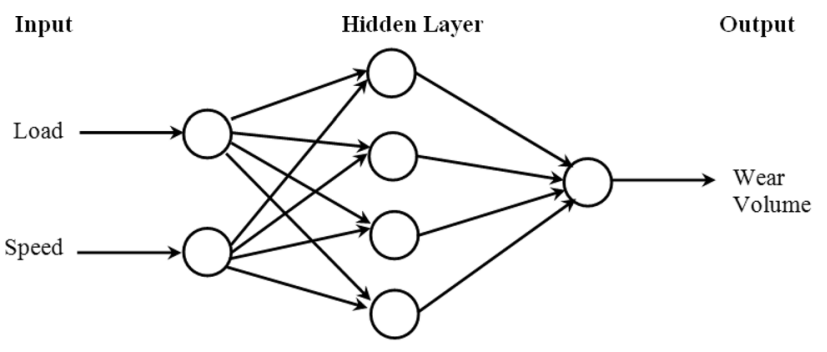

(a)

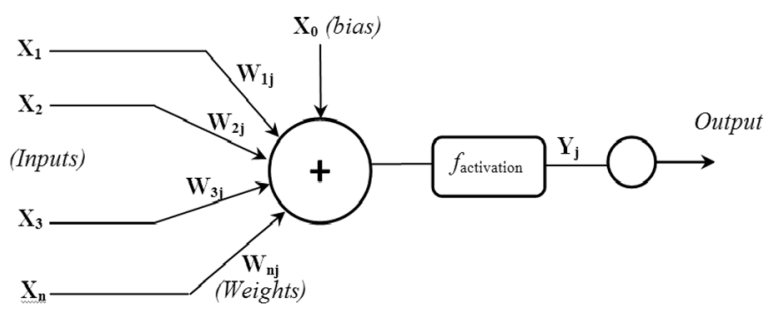

(b)

Fig. 2 a ANN network architecture, b individual neuron architecture 
Fig. 3 Variation of abrasive wear volume against sliding distance for different loads

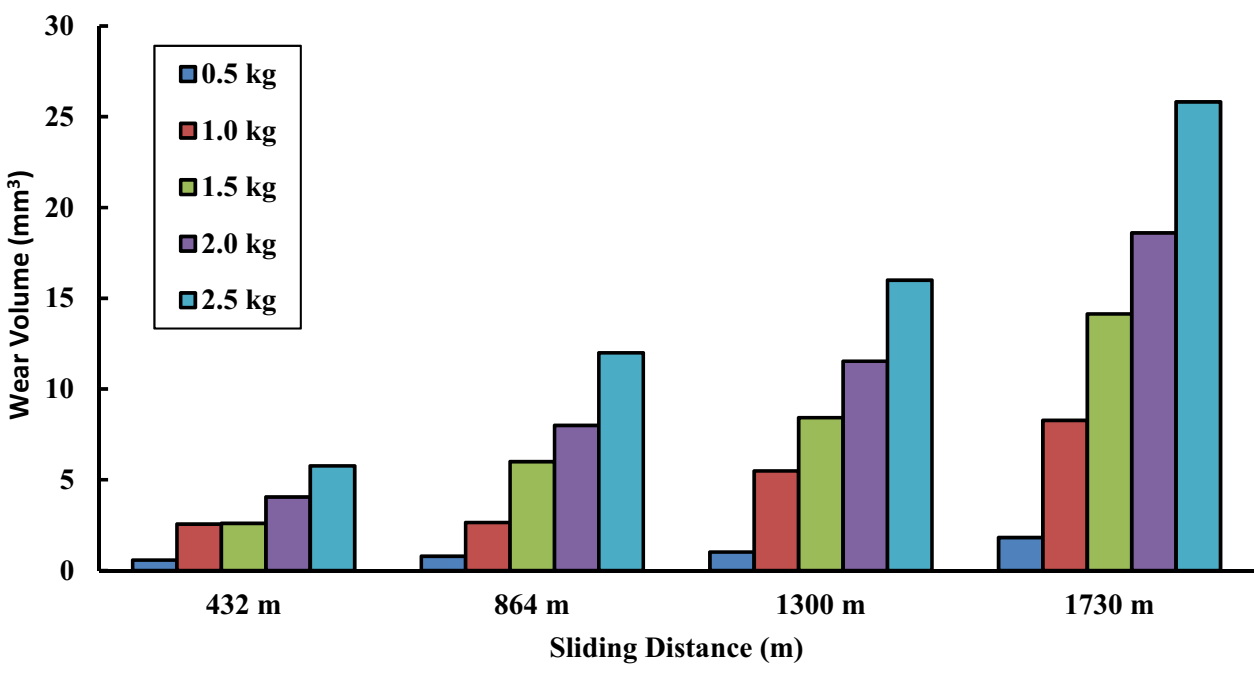

Table 3 Test parameters

\begin{tabular}{lrlrl}
\hline Term & Coef & SE Coef & $T$ value & $P$ value \\
\hline Constant & 5.25 & 1.86 & 2.82 & 0.018 \\
Speed & -4.24 & 1.23 & -3.43 & 0.006 \\
Load & -2.86 & 1.23 & -2.32 & 0.043 \\
Sliding distance & -0.49 & 1.23 & -0.39 & 0.702 \\
Speed*speed & 0.38 & 1.20 & 0.32 & 0.758 \\
Load*load & 3.99 & 1.20 & 3.32 & 0.008 \\
Sliding distance*sliding & -0.64 & 1.20 & -0.53 & 0.608 \\
$\quad$ distance & & & & \\
Speed*load & 2.40 & 1.61 & 1.49 & 0.168 \\
Speed*sliding distance & 1.16 & 1.61 & 0.72 & 0.488 \\
Load*sliding distance & 0.00 & 1.61 & 0.00 & 0.998 \\
\hline
\end{tabular}

$(\mathrm{Net})_{j}=\sum_{i=0}^{n} W_{i j} \cdot X_{j}+X_{0}$

where $X_{1}, X_{2}, \ldots X_{n}$ represent each input parameter, $W_{1 j}$, $W_{2 j}, \ldots \ldots, W_{n j}$ refers to the weights, $n$ is the number of inputs to $j^{\text {th }}$ neuron and $X_{0}$ is bias and $f_{\text {activation }}$ is the $j^{\text {th }}$ neuron activation function. In this study, abrasive wear volume is predicted using the hidden layer and hyperbolic tan-sigmoid activation function. The tan-sigmoid function is represented by Eq. 5:

$Y_{j}=\frac{2}{1+e^{\left(-2 \times \mathrm{Net}_{j}\right)}}-1$

The generated output is compared with the expected output in back-propagation scheme and the error is estimated for every output neuron. The error is computed using Eq. 6 given below: error $=\sum_{j}(\text { error })_{j}=\sum_{j} \frac{1}{2}\left(E_{j}-Y_{j}\right)^{2}$

$Y_{j}$ represents output value of the $j^{\text {th }}$ output neuron and $E_{j}$ is the expected value of the $j^{\text {th }}$ neuron in the above equation. These errors are returned to each neuron on the forward layer from the output layer. The mechanism is replicated layer by layer and network convergence causing the linking weight is renewed by each neuron. The back-propagation algorithm, Levenberg-Marquardt (TRAINLM), is used to build a network as it is precise in related approximations of functions and is included in the MATLAB ANN toolbox.

Weight and bias changes are made according to the following transfer function provided by Eq. 7 .

$\Delta W_{i j}=-\left(J^{T} \cdot J+\mu \cdot I\right)^{-1} \cdot J^{T} \cdot($ error function $)$

where $J$ represents the Jacobian matrix of each error difference and $\mu$ is a scalar.

As the input and output variables are spread over the wide range of values, they cannot be trained by the neural network. These values of the input neurons must be pretreated by normalising and transforming them to fall within the +1 and -1 range. The normalised value of each raw input is estimated according to Eq. 8:

$X_{i}=\frac{2}{d_{\mathrm{mx}}-d_{\mathrm{mn}}}\left(d_{\mathrm{mx}}-d_{\mathrm{mn}}\right)-1$

where $d_{\mathrm{mx}}$ and $d_{\mathrm{mn}}$ represent the maximum and minimum values of raw input parameter values respectively. 
Table 4 ANOVA table for abrasive wear

\begin{tabular}{|c|c|c|c|c|c|c|c|}
\hline Source & $\mathrm{DF}$ & Seq SS & Contribution (\%) & Adj SS & Adj MS & $F$ value & $P$ value \\
\hline Model & 9 & 662.181 & 76.07 & 662.181 & 73.576 & 3.53 & 0.031 \\
\hline Linear & 3 & 360.477 & 41.41 & 360.477 & 120.159 & 5.77 & 0.015 \\
\hline Speed & 1 & 245.538 & 28.21 & 245.538 & 245.538 & 11.79 & 0.006 \\
\hline Load & 1 & 111.713 & 12.83 & 111.713 & 111.713 & 5.36 & 0.043 \\
\hline Sliding distance & 1 & 3.226 & 0.37 & 3.226 & 3.226 & 0.15 & 0.702 \\
\hline Square & 3 & 244.980 & 28.14 & 244.980 & 81.660 & 3.92 & 0.043 \\
\hline Speed*speed & 1 & 0.091 & 0.01 & 2.096 & 2.096 & 0.10 & 0.758 \\
\hline Load*load & 1 & 239.044 & 27.46 & 229.359 & 229.359 & 11.01 & 0.008 \\
\hline Sliding distance*sliding distance & 1 & 5.845 & 0.67 & 5.845 & 5.845 & 0.28 & 0.608 \\
\hline Two-way interaction & 3 & 56.724 & 6.52 & 56.724 & 18.908 & 0.91 & 0.471 \\
\hline Speed*load & 1 & 45.936 & 5.28 & 45.936 & 45.936 & 2.21 & 0.168 \\
\hline Speed*sliding distance & 1 & 10.788 & 1.24 & 10.788 & 10.788 & 0.52 & 0.488 \\
\hline Load*sliding distance & 1 & 0.000 & 0.00 & 0.000 & 0.000 & 0.00 & 0.998 \\
\hline Error & 10 & 208.256 & 23.93 & 208.256 & 20.826 & & \\
\hline Lack-of-fit & 5 & 127.701 & 14.67 & 127.701 & 25.540 & 1.59 & 0.313 \\
\hline Pure error & 5 & 80.555 & 9.25 & 80.555 & 16.111 & & \\
\hline Total & 19 & 870.437 & 100.00 & & & & \\
\hline $\mathrm{R}^{2}=0.8607$ & & & & & & & \\
\hline
\end{tabular}

\section{Results and Discussion}

\section{Experimental Results}

The abrasive wear volume test results against different sliding distance for various loads are shown in Fig. 3. It is observed that the wear volume increases with rise in load as well as sliding distance. Each test was repeated three times and average of three readings was considered for computation. Substantial weight loss was obtained by varying the normal load between $4.905 \mathrm{~N}(0.5 \mathrm{~kg})$ and $24.525 \mathrm{~N}(2.5 \mathrm{~kg})$ throughout all the experiments. The angular velocity of the disc was varied for each of the experiments. The sliding track radius was adjusted for each trial to ensure that the specimen always passes over the fresh abrasive, allowing the variation in the sliding velocity from 0.125 to $2.7 \mathrm{~m} / \mathrm{s}$. Although the temperature has not

\section{Normal Probability Plot}

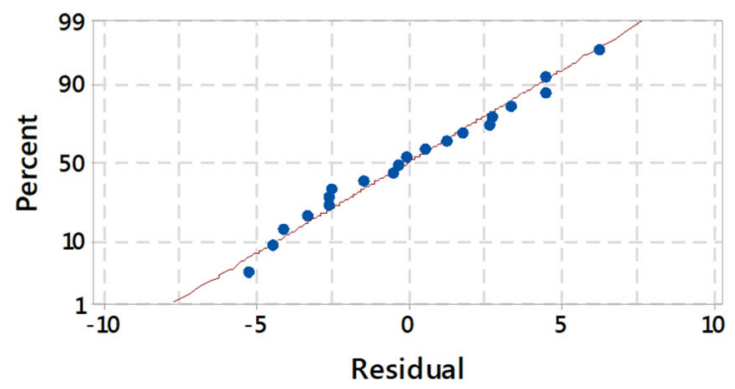

been measured, the temperature rose as the sliding distance is increased. This experimental dataset was utilised for training and validating the designed artificial neural network.

\section{Results Using Response Surface Methodology}

For the full quadratic model, the significance test is carried out. In Table 3, the calculated wear rate regression coefficients are shown. The wear rate recorded for the 20 experiment runs for the defined levels of process parameter levels is shown in Table 4 . The $R^{2}$ derived from the test results for abrasive wear was 86.07 per cent. This indicates that the model built can efficiently describe the relation between the desired response and the process parameters. From its $P$ values, the higher significant parameters $(P<0.05)$ and the non-significant parameters $(P>0.10)$

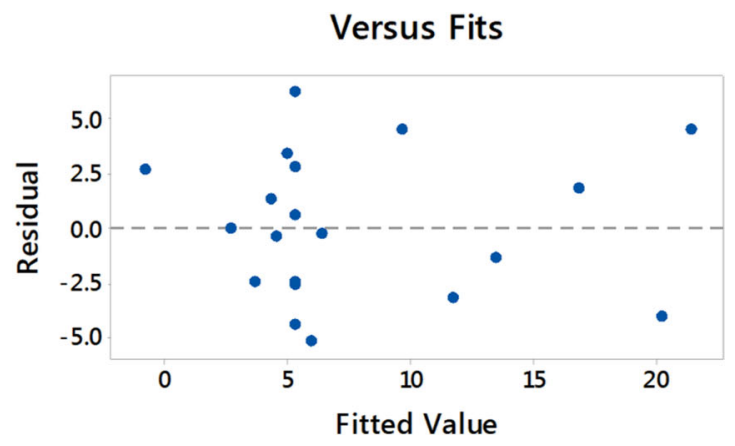

Fig. 4 Normal probability plot and versus fits for abrasive wear 
(a)
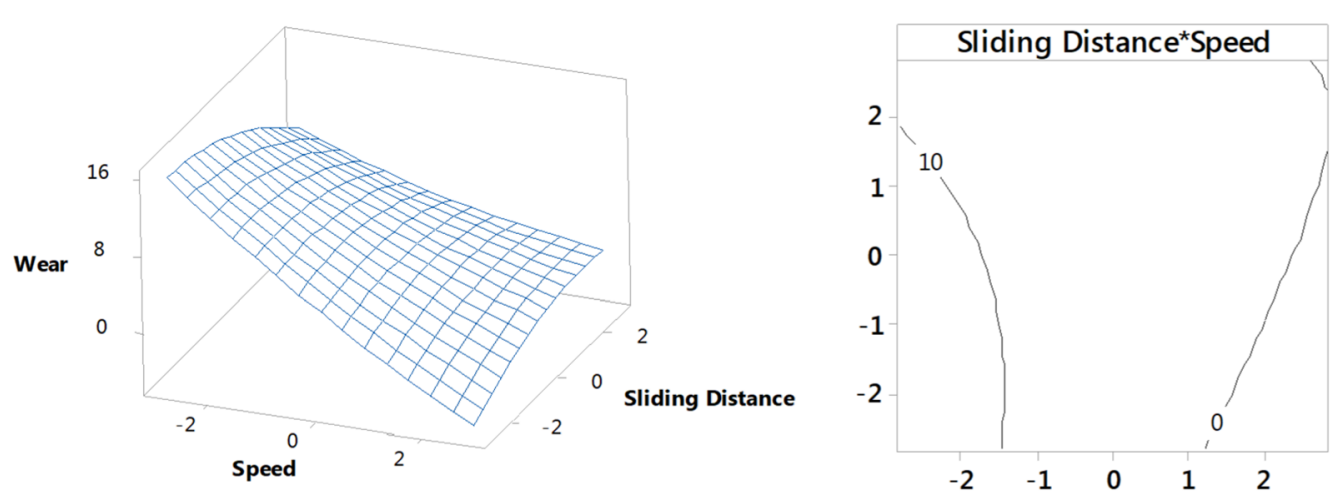

(b)
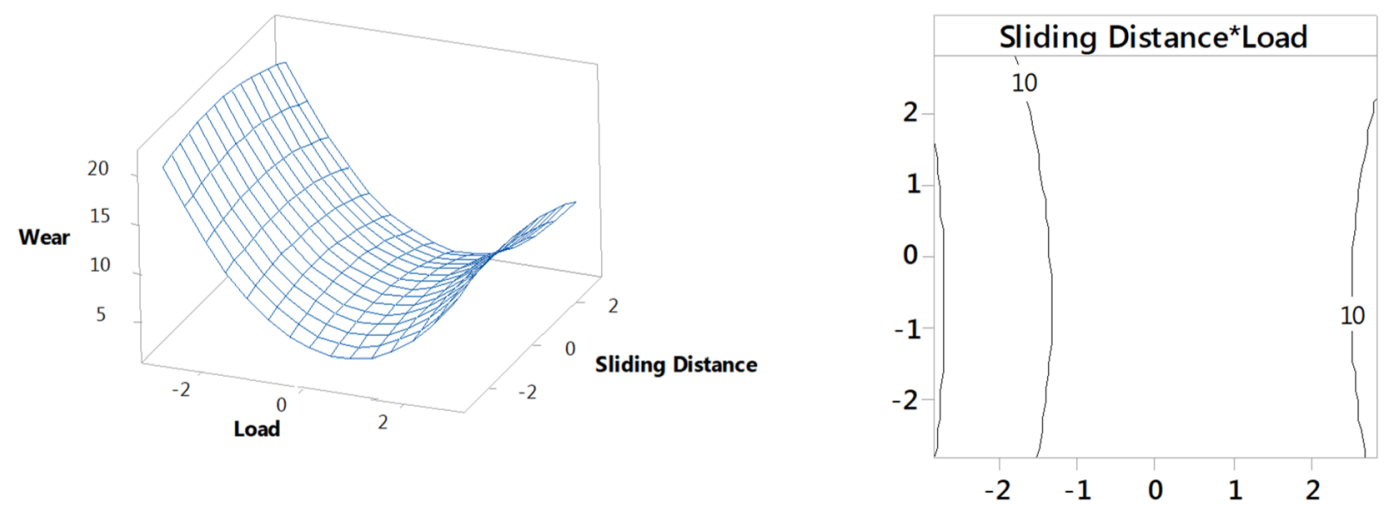

(c)
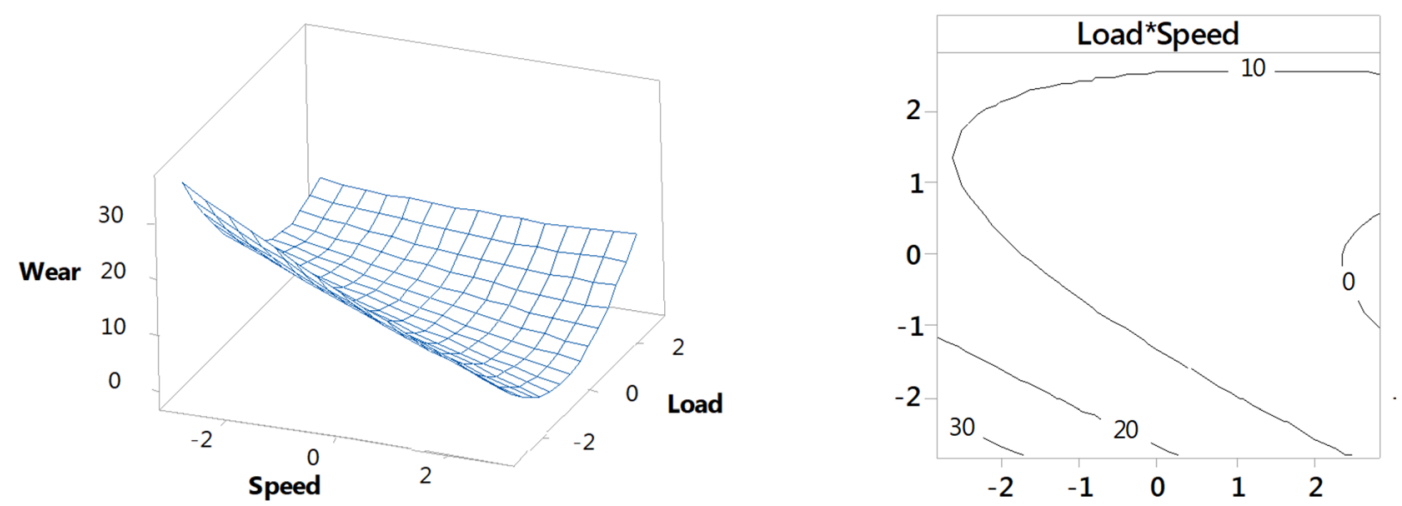

Fig. 5 Abrasive wear surface and contour plot of a sliding distance and speed; b sliding distance and load; c load and speed

were identified. The ANNOVA results listed in Table 4, based on its $P$ values (0.006), reveal that the disc speed and second order of load has the highest significant effect on the wear rate. The relation for wear volume deduced is:

$$
\begin{aligned}
\text { Wear volume }= & 5.25-2.521 \mathrm{~S}-1.701 \mathrm{~L}-0.289 \mathrm{D}+0.135 \mathrm{~S} * \mathrm{~S} \\
& +1.410 \mathrm{~L} * \mathrm{~L}-0.225 \mathrm{D} * \mathrm{D}+0.847 \mathrm{~S} * \mathrm{~L} \\
& +0.411 \mathrm{~S} * \mathrm{D}+0.001 \mathrm{~L} * \mathrm{D}
\end{aligned}
$$

where $S$ is the speed (rpm), $L$ is the load (N) and $D$ denotes the sliding distance (m). In Eq. 9, the negative sign of the speed, load and sliding distance coefficient suggests that the overall wear rate is decreased. Linear, square and interaction terms have more impact on wear value. The interaction effect between all process parameters does not influence the wear volume much.

Selecting the new parameter set for predicting wear behaviour, this derived model is checked for its precision. The results derived by the model are compared to experimental data for the identified parameter levels (Table 7). The experimental results indicate that the formulated model predicts the wear behaviour reliably and effectively.

\section{Adequacy of the Model}

The RSM was implemented to predict the abrasive wear of PTFE pin for dry sliding conditions on a rotating disc. The process variables and their impact on pin wear was estimated using analysis of variance (ANOVA). The 
Fig. 6 Interaction pots for wear

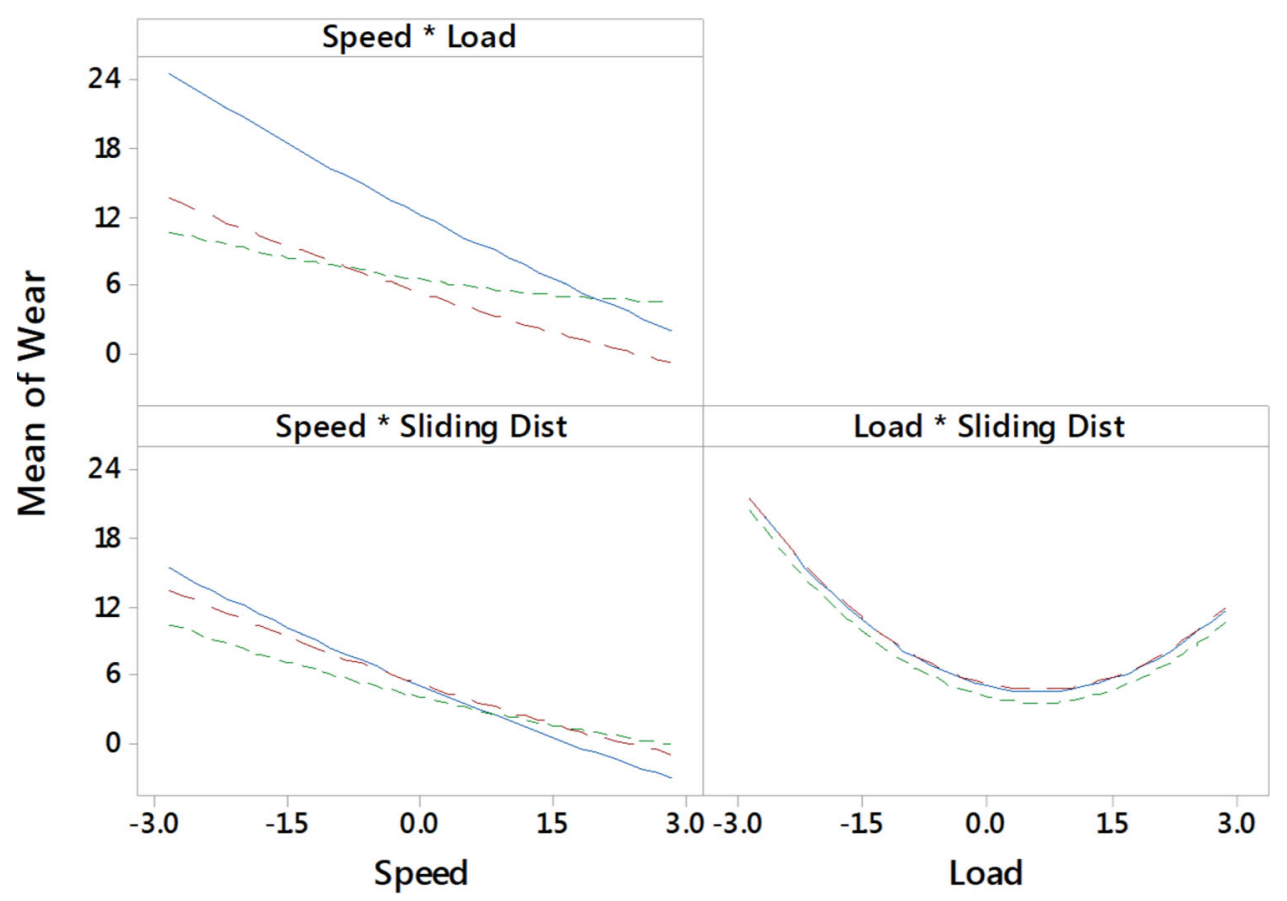

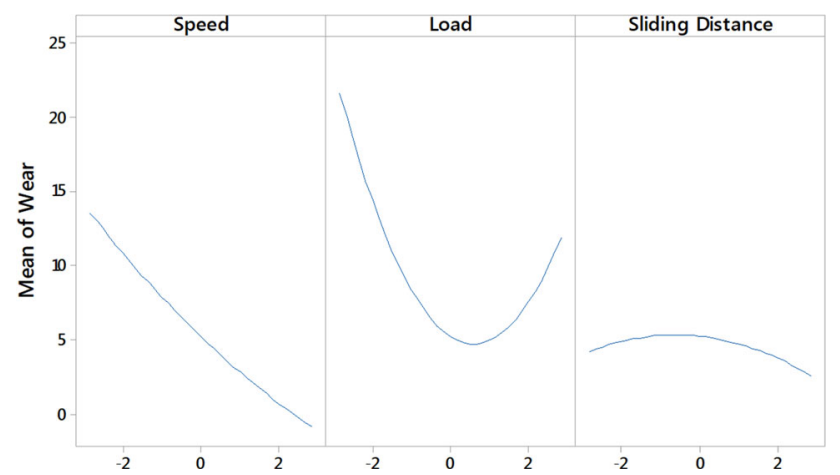

Fig. 7 Effect of process parameters on abrasive wear

ANNOVA was carried out for $95 \%$ confidence level. The precision of the developed model was verified by the significance of the regression model, coefficient model and the lack of fit. If the F value of lack of fit is lower than standard $F$ value (which is 5), the developed model is adequate. In this study, as F value for lack of fit is 1.59 , the model is adequate.

Figure 4 exhibits the normal probability plot of residuals for wear rate and it is observed that the residuals are distributed near the line, and the developed model is appropriate.

\section{Effect of Process Parameters on the Wear Rate}

Effect of Load on Abrasive Wear Rate In surface and contour plots (Fig. 5), the influence of different parameters is shown on the abrasive wear volume of the pin material.

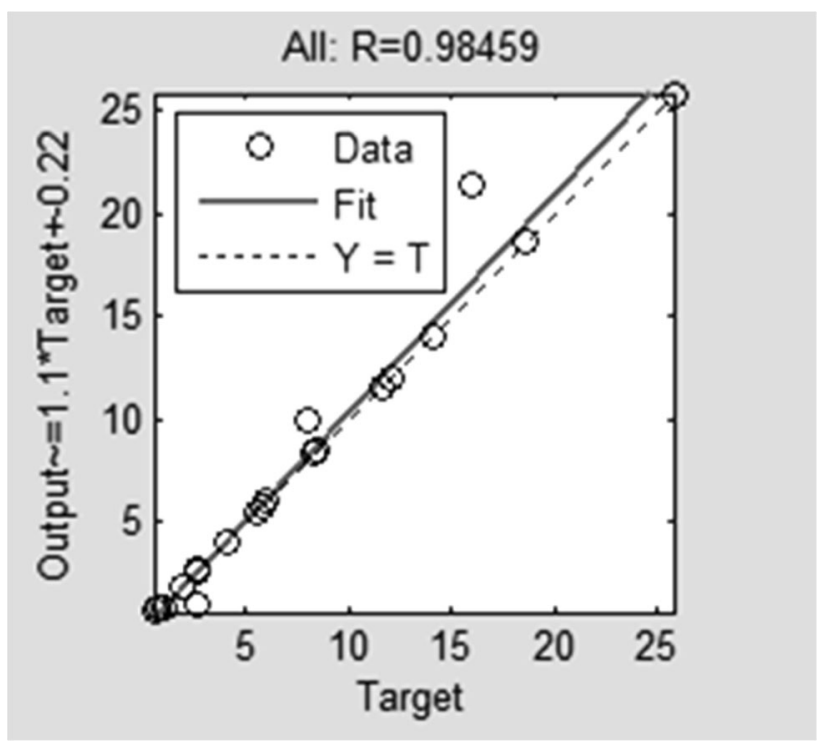

Fig. 8 3-10-1 ANN regression plot for wear prediction

Table 5 List of process variable

\begin{tabular}{llllc}
\hline Parameters & Minimum & Average & Maximum & Std. deviation \\
\hline Speed (RPM) & 250 & 750 & 1250 & 286.7696 \\
Load (N) & 4.905 & 14.715 & 24.525 & 7.11402 \\
Sliding distance (m) & 432 & 1081 & 1730 & 496.68665 \\
\hline
\end{tabular}


Table 6 ANN characteristics

\begin{tabular}{ll}
\hline Parameter & Specification \\
\hline $\begin{array}{l}\text { Number of hidden layers } \\
\text { Number of neurons in the hidden layer }\end{array}$ & 10 \\
$\begin{array}{l}\text { Number of neurons in the input layer } \\
\quad \text { (inputs) }\end{array}$ & \\
$\begin{array}{l}\text { Number of neurons in the output layer } \\
\quad \text { (outputs) }\end{array}$ & \\
Activation function & tan-sigmoid (TANSIG) \\
Training function & Levenberg-Marquardt \\
(TRAINLM) \\
Performance function & Mean square error (MSE) \\
Number of epochs to end training & 1000 \\
\hline
\end{tabular}

Table 7 Comparison between experimental, ANN and RSM predicted abrasive wear

\begin{tabular}{lcclclc}
\hline $\begin{array}{l}\text { Sr. } \\
\text { no }\end{array}$ & $\begin{array}{l}\text { Motor } \\
\text { speed } \\
(\mathrm{RPM})\end{array}$ & $\begin{array}{l}\text { Load } \\
(\mathrm{N})\end{array}$ & $\begin{array}{l}\text { Expt. wear } \\
\text { volume } \\
\left(\mathrm{mm}^{3}\right)\end{array}$ & $\begin{array}{l}\text { Sliding } \\
\text { distance } \\
(\mathrm{m})\end{array}$ & $\begin{array}{l}\text { ANN } \\
\text { wear } \\
\text { volume } \\
\left(\mathrm{mm}^{3}\right)\end{array}$ & $\begin{array}{l}\text { RSM } \\
\text { wear } \\
\text { volume } \\
\left(\mathrm{mm}^{3}\right)\end{array}$ \\
\hline 1 & 250 & 4.905 & 0.58 & 432 & 0.5992 & 0.58804 \\
2 & 250 & 9.81 & 2.56 & 432 & 2.5594 & 2.63267 \\
3 & 250 & 14.71 & 2.60 & 432 & 2.60296 & 2.25138 \\
4 & 250 & 19.62 & 4.05 & 432 & 4.0345 & 4.53746 \\
5 & 250 & 24.52 & 5.77 & 432 & 5.7373 & 5.25138 \\
6 & 500 & 4.905 & 0.791 & 864 & 0.807793 & 0.55138 \\
7 & 500 & 9.81 & 2.65 & 864 & 2.649589 & 2.25138 \\
8 & 500 & 14.71 & 6 & 864 & 5.965 & 6.32561 \\
9 & 500 & 19.62 & 8 & 864 & 7.945 & 5.25138 \\
10 & 500 & 24.52 & 12 & 864 & 11.905 & 13.4612 \\
11 & 750 & 4.905 & 1.02 & 1300 & 1.038018 & 1.60232 \\
12 & 750 & 9.81 & 5.49 & 1300 & 5.45812 & 4.26748 \\
13 & 750 & 14.71 & 8.42 & 1300 & 8.359414 & 9.72503 \\
14 & 750 & 19.62 & 11.5 & 1300 & 11.44445 & 10.2514 \\
15 & 750 & 24.52 & 16.0 & 1300 & 15.865 & 16.1328 \\
16 & 1000 & 4.905 & 1.81 & 1730 & 1.820761 & 1.80103 \\
17 & 1000 & 9.81 & 8.28 & 1730 & 8.22121 & 8.96026 \\
18 & 1000 & 14.71 & 14.1 & 1730 & 14.02311 & 14.6127 \\
19 & 1000 & 19.62 & 18.6 & 1730 & 18.44296 & 16.8308 \\
20 & 1000 & 24.5 & 25.8 & 1730 & 25.58076 & 23.3451 \\
\hline & & & & & & \\
\hline
\end{tabular}

Table 8 Comparison of prediction between ANN and RSM

\begin{tabular}{lll}
\hline Methodology used and predicted error & ANN & RSM \\
\hline Standard deviation $(\sigma)$ & 5.2010 & 5.306697 \\
Mean squared error (MSE) & 0.006189 & 1.2820 \\
Root mean square error (RSME) & 0.079 & 1.132 \\
Mean absolute percentage error (MAPE) & 0.82054499 & $14,068,881$ \\
\hline
\end{tabular}

With an increase in load relative to the constant speed and sliding distance, the amount of pin wear increased. The interacting pressure of the surface is smaller at low loads and the specimen deformity is therefore very small. With the elevated load, contact stresses increase, leading to further damage to the surface. The elevated load allows the substance to be separated from the surface like debris, so that in fact, more material is removed due to trapping on high-pressure interfaces.

Effect of Speed on Wear Rate As the rotation rate is increased, the wear rate is decreased and high wear rates with low speed are observed because of the specimen's increased contact time with the counter front. As speed increases and the material is oxidised, the interfacial temperature also varies. This helps a rough and mechanically mixed coating to be laid on the components. This coating is resistant to removal and increases the wear of the surface considerably. When the protection of the hard layer is heavily mixed and the surface on the counter is less contacted, wear rate is minimised.

Effect of Sliding Distance on Wear Rate Figures 6 and 7 display the wear plot for sliding distance in terms of load and velocity. The wear rate was initially increased and decreased after a significant distance was reached. For the initial part, the wear rate increased with the sliding distance which may be due to interaction with the counter facing on the machined outer surface of the sample during the initial process. The matrix area on the pin surface is eliminated in this process and further material removal is done. The hard particles are lined with the surface and come in contact with the counter face as sliding distance keeps increasing.

\section{ANN Predicted Results}

The amount of abrasive wear of the PTFE pins was predicted using an artificial neural network model. The models are based on a forward-layer-back-propagation scheme trained using the Levenberg-Marquardt (TRAINLM) training function. The list of process variables is given in Table 5. The mean square error (MSE) function was used to predict performance. The model was trained using experimental databases generated by a series of laboratory tests. A ratio of 70:20:10 is used to compile the database. The ANN specifications are given in Table 6 . There are three input parameters and one output parameter. Two hidden layers were used to train the network. Recession analysis was performed to analyse the network response.

The designed artificial neural network accuracy was examined by the mean squared error (MSE) and the coefficient of multiple determinations, $R$. The ANN regression 

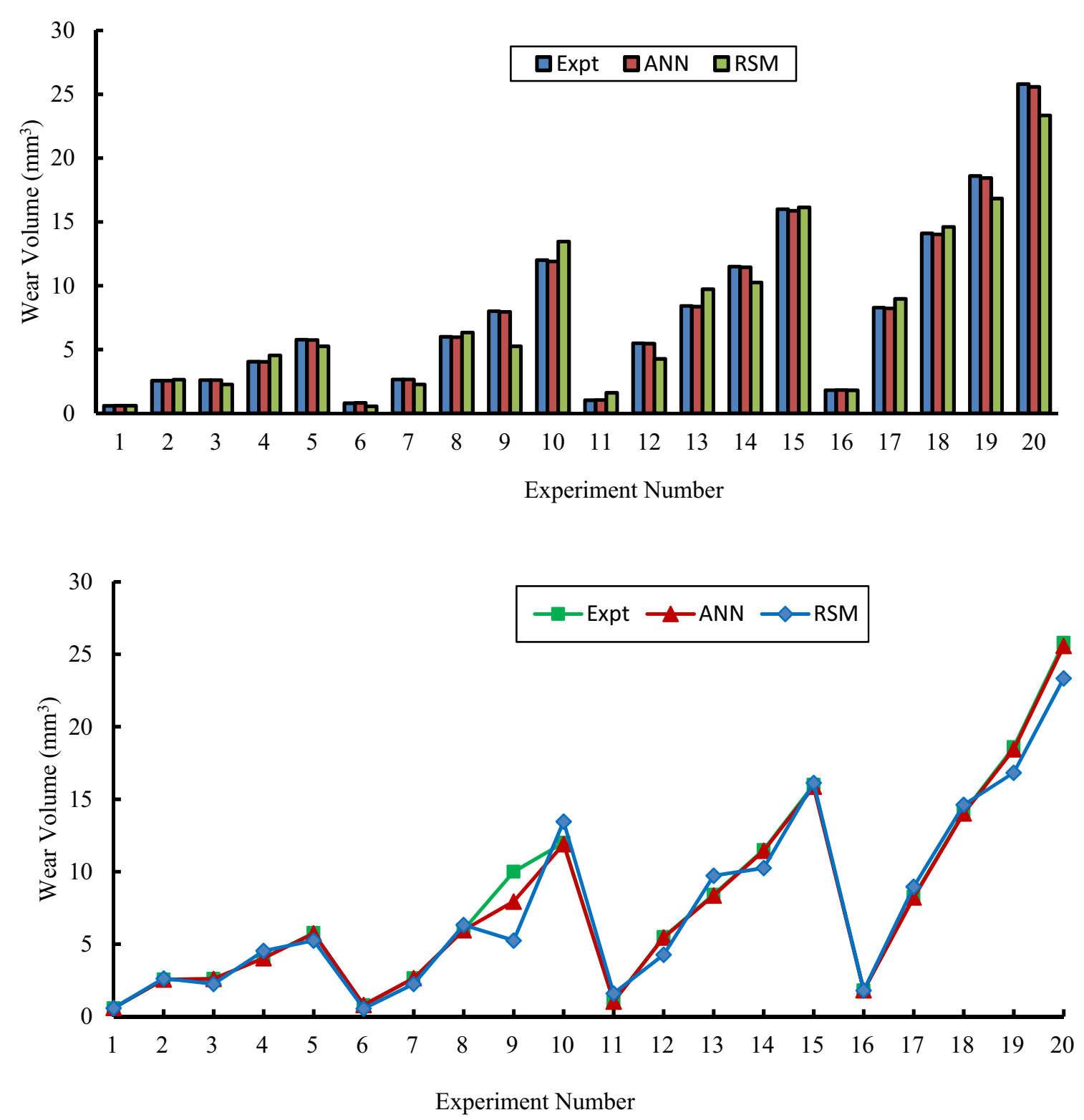

Fig. 9 Comparison between experimental, ANN and RSM predicted wear

plot (Fig. 8) for wear volume prediction shows the accurate prediction of wear volume by the trained network.

The estimation of the abrasive wear volume by ANN and RSM is given in Table 8. It was observed that ANN model accurately predicts the abrasive wear volume with close proximity to the experimental data points as compared to RSM.

\section{Comparison of ANN and RSM}

Both ANN and RSM designs are correlated with the expected value of abrasive wear volume in Table 8 . The prediction of the ANN and RSM models' results as regards absolute standard deviation and root average percentage square error is illustrated in Table 8. The correlation between experimental answers and expected RSM and ANN findings is shown in Fig. 9. The comparative study indicates that both models have successfully introduced stable responses to the estimation of independent responses variables. The ANN technology provided superior fitness for the performance responses relative to the RSM process.

Table 8 displays the RMSE and ABSD percentage for models developed using both methodologies and again, ANN modelling abrasive wear is strongly rationalised to forecast responses. Both the RSM and the ANN models need less time and resources for computing by using Minitab 16 programme test kits, and MATLAB software, respectively. The ANN model requires some iterative 
calculations, with correct results in the right choice of an ANN structure.

\section{Conclusions}

The present study utilises an in-house manufactured experimental test rig to examine the dry sliding wear of PTFE pin specimen on mild steel disc counterpart. The central composite design experimental architecture is implemented to design ANN and RSM models to predict abrasive wear of PTFE pin. The findings of this analysis are as follows:

1. The study was performed using the RSM-based CCD architecture. In the case of dry, sliding wear performance predictions, the established statistical model based on test data for abrasive wear volumes has been found to be satisfactory; the abrasive wear estimates predicted by both models are in line with the experimental findings.

2. For the development of an ANN model, a multilayered feedforward back-propagation neural network with a 3-10-1 structure has been used.

3. The validation studies carried out on both RSM and ANN models demonstrated that abrasive wear volume can be predicted correctly and accurately.

4. From the ANOVA results, the disc speed $(S)$ is found to be the major parameter influencing the abrasive wear volume in dry sliding wear phenomena of PTFE pin with a contribution of $28.21 \%$. The rise in the disc speed $(S)$ results in increased abrasive wear. The second most influential parameter is the load $(L)$ with an abrasive wear contribution of $12.83 \%$.

5. Established ANN and RSM models were adequate and aligned with experimental findings for exact and robust predictions of abrasive wear. However, the ANN methodology yielded superior performance results compared to the RSM process.

Funding This work did not receive any funding from any source.

\section{References}

1. F. Bowden, D. Tabor, The Friction and Lubrication of Solids (Clarendon Press, Oxford, 1986).

2. K. Johnson, Contact Mechanics (Cambridge University Press, Cambridge, 1985).

3. D. Hills, D. Nowell, Mechanics of Fretting Fatigue (Kluwer, Dordrecht, 1994).

4. I. Goryacheva, Contact Mechanics in Tribology (Kluwer Academic Publishing, Dordrecht, 1998).

5. J. Barber, Contact Mechanics (Springer, New York, NY, 2018).
6. P. Nayak, Random process model of rough surfaces. J. Lubric. Technol. 93, 398-407 (1971)

7. J. Li, J. Zhang, W. Ge, X. Liu, Multi-scale methodology for complex systems. Chem. Eng. Sci. 59, 1687-1700 (2004)

8. B. Bhushan, J.N. Israelachvili, U. Landman, Nanotribology: friction, wear, and lubrication at the atomic scale. Nature 374, 607-616 (1995)

9. A.A. Yevtushenko, P. Grzes, The FEM-modelling of the frictional heating phenomenon in the pad/disc tribosystem (a review). Numer. Heat Transf. A. 58, 207-226 (2010)

10. Y. Xu, R. Jackson, Boundary element method (BEM) applied to the rough surface contact vs. BEM in computational mechanics. Friction 6, 1-13 (2018)

11. V. Popov, M. Heß, Method of Dimensionality Reduction in Contact Mechanics and Friction (Springer, Berlin, 2015).

12. I. Argatov, Y. Fadin, Asymptotic modelling of the long-period oscillations of tribological parameters in the wear process of metals under heavy-duty sliding conditions with application to structural health monitoring. Int. J. Eng. Sci. 48, 835-847 (2010)

13. V. Popov, S. Psakhie, Numerical simulation methods in tribology. Tribol. Int. 40, 916-923 (2007)

14. A. Vakis, V. Yastrebov, J. Scheibert, L. Nicola, D. Dini, C. Minfray, Modeling and simulation in tribology across scales: an overview. Tribol. Int. 125, 169-199 (2018)

15. Y. Ali, R. Rahman, R. Hamzah, Acoustic emission signal analysis and artificial intelligence techniques in machine condition monitoring and fault diagnosis: a review. J. Teknol. 69, 121-126 (2014)

16. E. Bucholz, C. Kong, K. Marchman, W. Sawyer, S. Phillpot, S. Sinnott, Data-driven model for estimation of friction coefficient via informatics methods. Tribol. Lett. 47, 211-221 (2012)

17. S. Jones, R. Jansen, R. Fusaro, Preliminary investigation of neural network techniques to predict tribological properties. Tribol. Trans. 40, 312-320 (1997)

18. K. Friedrich, R. Reinicke, Z. Zhang, Wear of polymer composites. Proc. Inst. Mech. Eng. J. 216, 415-426 (2002)

19. Z. Jiang, Z. Zhang, K. Friedrich, Prediction on wear properties of polymer composites with artificial neural networks. Compos. Sci. Technol. 67, 168-176 (2007)

20. H. Kadi, Modelling the mechanical behavior of fiber-reinforced polymeric composite materials using artificial neural networksa review. Compos. Struct. 73, 1-23 (2006)

21. K. Velten, R. Reinicke, K. Friedrich, Wear volume prediction with artificial neural networks. Tribol. Int. 33(10), 731-736 (2000)

22. O. Bratcu, L. Tomescu, O. Bologa, Tribological Behaviour of PTFE + Glass Fiber Composites Used for Axial Bearing Under Water Lubrication. The Annals of University Dunarea De Jos of Galati, Fascicle VIII, ISSN 1221-4590, Tribology, pp. 65-68 (2005)

23. R. Quiza, L. Figueira, J. Davim, Comparing statistical models and artificial neural networks on predicting the tool wear in hard machining D2 AISI steel. Int. J. Adv. Manuf. Technol. 37, 641-648 (2013)

24. A. Ghasempoor, T. Moore, J. Jeswiet, On-line wear estimation using neural networks. Proc. Inst. Mech. Eng. B 212, 105-112 (1998)

25. D. Aleksendrić, D.C. Barton, Neural network prediction of disc brake performance. Tribol. Int. 42(7), 1074-1080 (2009)

26. J. Bao,, M. Tong, Z. Zhu, Y. Yin, Intelligent tribological forecasting model and system for disc brake, in 24th Chinese Control and Decision Conference (CCDC), pp. 3870-3874 (2012).

27. Z. Zhang, Z. Jiang, Wear of multi-scale phase reinforced composites, in Tribology of Nanocomposites, Materials Forming, 
Machining and Tribology. ed. by J. Davim (Springer, Berlin, 2013), pp. 79-100

28. A. Shebani, S. Iwnicki, Prediction of wheel and rail wear under different contact conditions using artificial neural networks. Wear 406407, 173-184 (2018)

29. A. Fathy, A.A. Megahed, Prediction of abrasive wear rate of in situ $\mathrm{Cu}-\mathrm{Al}_{2} \mathrm{O}_{3}$ nano-composite using artificial neural networks. Int. J. Adv. Manuf. Technol. 62, 953-963 (2012)

30. A.A. Agbeleye, D.E. Esezobor, J.O. Agunsoye, S.A. Balogun, A.A. Sosimi, Prediction of the abrasive wear behavior of heattreated aluminum-clay composites using an artificial neural network. J. Taibah Univ. Sci. 12(2), 235-240 (2018)

31. M.R. Phate, S.B. Toney, Modelling and prediction of WEDM performance parameters for $\mathrm{Al} / \mathrm{SiCp}$ MMC using dimensional analysis and artificial neural network. J. Eng. Sci. Technol. 22(2), 468-476 (2019)

32. M.R. Phate, S.B. Toney, V.R. Phate, Analysis of machining parameters in WEDM of $\mathrm{Al} / \mathrm{SiCp} 20 \mathrm{MMC}$ using Taguchi based grey-fuzzy approach. Model. Simul. Eng. 2019, 1-13 (2019)

33. M.R. Phate, S.B. Toney, V.R. Phate, Prediction and analysis of surface roughness in WEDM of Al/Gr/Cp5 MMC using RSM and ANN. Ind. Eng. J. 12(12), 1-14 (2019)

34. S. Bhaumik, S.D. Pathak, S. Dey, S. Datta, Artificial intelligence based design of multiple friction modifiers dispersed castor oil and evaluating its tribological properties. Tribol. Int. 140, 105813 (2019). https://doi.org/10.1016/j.triboint.2019.06.006

35. I.I. Argatov, Y.S. Chai, Artificial neural network modelling of sliding wear. Proc. Inst. Mech. Eng. Part J J. Eng. Tribol. (2020). https://doi.org/10.1177/1350650120925582
36. B.P. Chang, H. MdAkil, M.G. Affendy, A. Khan, R.B.M. Nasir, Comparative study of wear performance of particulate and fiberreinforced nano-ZnO/ultra-high molecular weight polyethylene hybrid composites using response surface methodology. Mater. Des. 63, 805-819 (2014). https://doi.org/10.1016/j.mat des.2014.06.031

37. S.C. Vettivel, N. Selvakumar, R. Narayanasamy, N. Leema, Numerical modelling, prediction of $\mathrm{Cu}-\mathrm{W}$ nano powder composite in dry sliding wear condition using responsesurface methodology. Mater. Des. 50, 977-986 (2013)

38. N. Radhika, R. Raghu, Parametric study of dry sliding wear behaviour offunctionally graded Al LM25/Si3N4 composite by response surface methodology. Adv. Compos. Lett. 24(6), $130-136$ (2015)

39. C. Anand Chairman, S.P. KumareshBabu, M. DuraiSelvam, K.R. Balasubramanian, Investigation on two-body abrasive wear behavior of titanium carbide filled glassfabric-epoxy compositesa box-behnken approach. Int. J. Eng. Sci. Technol. 3(4), 119-129 (2011). https://doi.org/10.4314/ijest.v3i4.68547

40. N. Radhika, R. Raghu, Study on three body abrasive wear behaviour of functionally graded $\mathrm{Al} / \mathrm{TiB} 2$ composite using response surface methodology. Part. Sci. Technol. (2017). https://doi.org/10.1080/02726351.2017.1305024

Publisher's Note Springer Nature remains neutral with regard to jurisdictional claims in published maps and institutional affiliations. 